\title{
The attenuative effects of oral resveratrol on renal changes induced by vanadium injection in rats
}

\author{
Soodabeh Zendeboodi ${ }^{\circledR}$, Abdolhamid Esmaili ${ }^{2}$, Ali Movahed ${ }^{3}$, Hossein Fatemikia ${ }^{4}$, Ali Jamshidi ${ }^{5}$, Matin \\ Nazari $^{5}$, Hosein Heydari ${ }^{5}$, Ramin Seyedian ${ }^{6 *(\mathbb{D}}$
}

${ }^{1}$ Department of Internal Medicine, Bushehr University of Medical Sciences, Bushehr, Iran

${ }^{2}$ Department of Pathology, Bushehr University of Medical Sciences, Bushehr, Iran

${ }^{3}$ The Persian Gulf Tropical Research Center, Biochemistry Group, Bushehr University of Medical Sciences, Bushehr, Iran

${ }^{4}$ Department of Physiology, School of Medicine, Shiraz University of Medical Sciences, Shiraz, Iran

${ }^{5}$ Student Research Committee, Bushehr University of Medical Sciences, Bushehr, Iran

${ }^{6}$ Department of Pharmacology, Bushehr University of Medical Sciences, Bushehr, Iran

\section{ART I C LE IN F O}

Article Type:

Original

\section{Article History:}

Received: 11 May 2018

Accepted: 13 November 2018

Published online: 18 January 2019

\section{Keywords:}

Ammonium metavanadate

Resveratrol

Tubular necrosis

Transforming growth factor $\beta 1$

Superoxide dismutase

\begin{abstract}
A B S T R A C T
Introduction: Resveratrol (trans-3,5,4'-trihydroxystilbene) as a polyphenol with potential antioxidant and anti-inflammatory properties is known as an effective herbal medicine in different disorders in rats.

Objectives: The present study was carried out to investigate the protective effects of oral consumption of resveratrol on vanadium induced renal injury in male Wistar rats.

Materials and Methods: Animals received either ammonium metavanadate (AMV, $5 \mathrm{mg}$ / $\mathrm{kg} / \mathrm{d}$, (intraperitoneally; 14 consecutive days) or resveratrol solution $(10 \mathrm{mg} / \mathrm{kg}$ and $50 \mathrm{mg} / \mathrm{kg}$, gastric gavage) along with AMV treatment. The last group received resveratrol alone (50 mg/ $\mathrm{kg}$, gastric gavage) for 4 weeks.

Results: AMV injection caused progressive tubular damages resembling acute tubular necrosis. Microscopic views revealed tubular attenuation and blebbing. In addition, progressive peritubular congestion of the capillaries observed while no evidence of renal fibrosis was present in trichrome staining. Further, levels of the renal transforming growth factor $\beta 1$ (TGF- $\beta 1$ ) as an index of fibrosis had no difference in treated animals as compared with the control ( $13.4 \pm 1.2$ versus $11.24 \pm 0.93 \mathrm{pg} / \mathrm{mg}$ protein) at the $P<0.05$. However, in AMVtreated animals receiving the higher dose of resveratrol $(50 \mathrm{mg} / \mathrm{kg})$, the renal superoxide dismutase (SOD) activity, showed no difference as compared with the saline-treated rats $(42 \pm 1.3$ versus $51 \pm 1.4)$.

Conclusions It is evident that AMV injection had no ability to induce renal fibrosis in rats while it evokes renal destructive lesions based on pathological results and enzyme levels. Moreover, our preliminary results suggest that resveratrol in high dose $(50 \mathrm{mg} / \mathrm{kg})$ could confer a minor role against AMV induced renal tubular necrosis in rats due to pathological results.
\end{abstract}

Implication for health policy/practice/research/medical education:

Resveratrol is recently introduced as an effective antioxidant agent to ameliorate various nephropathic disorders. In this study, oral resveratrol at high dose (50 mg/kg, gastric gavage, 28 days) neutralized AMV (5 mg/kg/d, intraperitoneally, 14 consecutive days) induced biochemical changes in BUN and serum creatinine in rats. Additionally, this agent prevented renal SOD and TGF- $\beta 1$ activities while had minor preventive effects on the AMV induced tubulopathy.

Please cite this paper as: Zendeboodi S, Esmaili A, Movahed A, Fatemikia H, Jamshidi A, Nazari M, et al. The attenuative effects of oral resveratrol on renal changes induced by vanadium injection in rats. J Renal Inj Prev. 2019; 8(2): 127-132. DOI: 10.15171/jrip.2019.24.

\section{Introduction}

Vanadium is a hard and gray metal belongs to a group of elements like chromium, nickel and lithium which their importance in humans has not been strongly accepted.
Moreover, this is a critical finding that this agent can play an important role in the growth and confrontation with environmental toxins or carcinogens $(1,2)$. Diarrhea, irregular respiration, and ataxia are the common physical 
signs of vanadium intoxication which usually disappear after 48 hours in mice (3). Further, there are some reports indicating the inhibitory effects of the orthovanadate $\left(\mathrm{Na}_{3} \mathrm{VO}_{4}\right)$ on the renal sodium-potassium pump, skeletal muscles and heart (4). Renal toxicity is due to the high accumulation of this element in animals and originated from its capacity to induce the oxidative stress molecules at the cellular level. Different agents have been used to protect the renal tissues against reactive oxygen species (ROS), one of which is resveratrol, a polyphenol present in the skin of grapes, blueberries, raspberries and, mulberries. This particular compound has been evaluated as a dietary supplement to counteract destructive oxidative stress in the human body (5). Additionally, resveratrol has several beneficial effects on different pathological conditions including hypertension, diabetes mellitus, inflammation and finally neuroprotection in laboratory animals. Researches have shown the protective role of this agent against renal diseases caused by oxidative stress. Furthermore, there is some evidence that resveratrol has preventive capacity on renal fibrotic process due to unilateral ureteral obstruction in animal studies (6). It is bearing in mind that subcutaneous injection of the ammonium metavanadate $\left(\mathrm{NH}_{4} \mathrm{VO}_{3}\right.$ or $\left.\mathrm{AMV}\right)$ solution could produce various degrees of kidney damage within 16 days (7).

\section{Objectives}

In this preliminary study, the renal attenuative effects of resveratrol on the destructive properties of the AMV were assessed based on the enzyme changes and pathological malformations in different experimental groups.

\section{Materials and Methods}

Animals and chemicals

Male Sprague Dawley rats were purchased from Ahvaz University Breeding Center, Iran. They were sexually mature and weighed 200-250 g. Animals were housed in polycarbonate cages (three animals in each) in an airconditioned room with free access to water and laboratory chow. They were kept at $20 \pm 2^{\circ} \mathrm{C}$ and maintained at 12 hours light-dark cycling, starting at 7 AM. AMV was purchased from Santa Cruz Company. Resveratrol was obtained from Biotivia, BioCeuticals International SrL, Italy. All other reagents were analytical grades from commercial sources.

\section{Experimental protocol}

Animals were randomly divided into five groups (contained 6 rats in each) for sacrificing after 28 days according to Table 1 .

AMV was dissolved in normal saline $(\mathrm{pH}$ 6.7) at the concentration of $5 \mathrm{mg} / \mathrm{mL}$, just before our experiment (8) and daily injected intraperitoneally for 14 consecutive days.
Table 1. Experimental protocol

\begin{tabular}{lcc}
\hline Groups & $\begin{array}{c}\text { Treatment (IP } \\
\text { injection) }\end{array}$ & $\begin{array}{c}\text { Gastric gavage (28 } \\
\text { days) }\end{array}$ \\
\hline Control & Saline (14 days) & Saline solution \\
Res 50 & Saline (14 days) & Resveratrol (50 mg/kg) \\
AMV (5 mg/kg) & AMV (14 days) & Saline solution \\
AMV $(5 \mathrm{mg} / \mathrm{kg})+$ Res 10 & AMV (14 days) & Resveratrol (10 mg/kg) \\
AMV (5 mg/kg)+Res 50 & AMV (14 days) & Resveratrol (50 mg/kg) \\
\hline
\end{tabular}

Abbreviations: AMV, ammonium metavanadate; Res, resveratrol.

All solutions were given orally in equal volume $(0.5 \mathrm{~mL})$ 10 minutes before intraperitoneal AMV injection and continued for 28 days.

They were weighed at the same time (7 AM) daily before our experiments (Figure 1) and mortalities were recorded for 28 days in all groups.

At the end of the study, all rats' weights were measured and the animals sacrificed under general anesthesia with ketamine injection (intraperitoneally). Blood samples collected from the heart were centrifuged at $2000 \mathrm{rpm}$ for 5 minutes and the concentrations of the biological parameters including serum creatinine, urea, sodium, and potassium were measured using an autoanalyzer (Olympus AU800) (9). At the same time, both kidneys were removed rapidly and washed with the cold phosphate buffer saline and weighed for each animal. The right kidneys were kept in formaldehyde solution (10\%) for Hematoxylin \& Eosin (H\&E) staining in addition to Masson's trichrome for finding pulmonary abnormalities and fibrosis respectively while the left kidneys were stored at $-80^{\circ} \mathrm{C}$ until the analysis. The processed kidney sections $(3-\mu \mathrm{m}$-thick) were evaluated with a pathologist unaware of our experiment. Two specimens from each case were inspected for 5 criteria including glomerular appearance, cytoplasmic vacuolization, peritubular capillary congestion, cytoplasmic attenuation, and finally

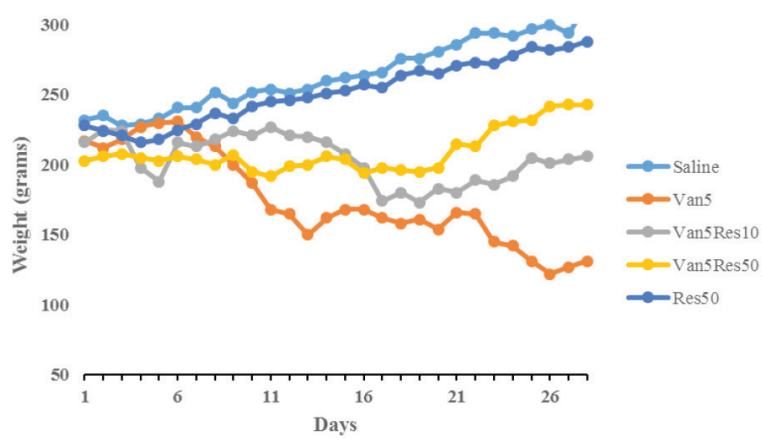

Figure 1. Weight variation curve of rats given AMV with or without resveratrol, as compared to control animals. Abbreviations: Van, vanadium; Res, resveratrol; $\mathrm{AMV}$, ammonium metavanadate. 


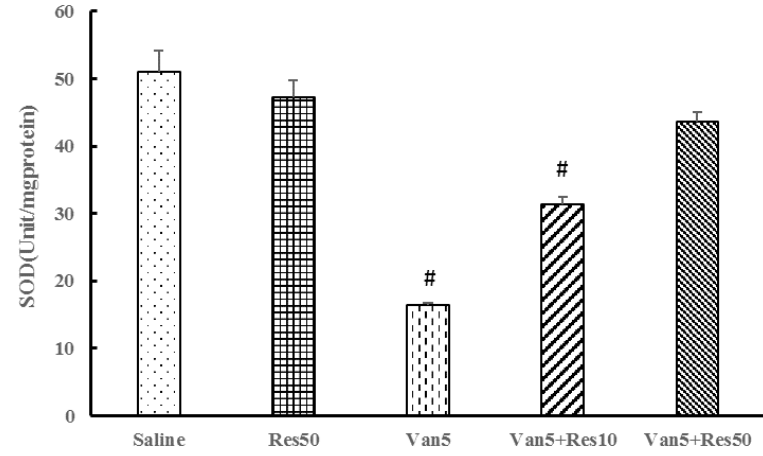

Figure 2. Renal activities of SOD enzyme at days 28 in rats injected with AMV (14 days) and resveratrol in two doses (10 and $50 \mathrm{mg} / \mathrm{kg}$ ) compared to the saline and resveratrol alone. \# Means significant differences versus control at $P<0.05$. Abbreviations: Van, vanadium; Res, resveratrol; SOD, superoxide dismutase; AMV, ammonium metavanadate.

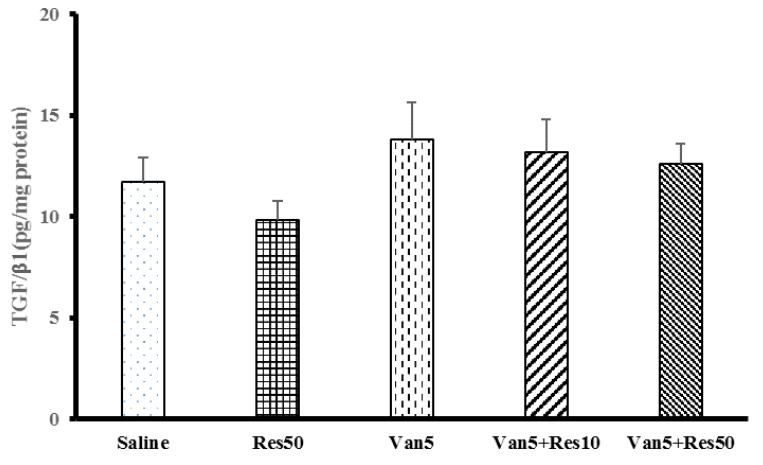

Figure 3. Active TGF- $\beta$ amounts in different groups. Abbreviations: Van, vanadium; Res, resveratrol; TGF- $\beta$, transforming growth factor $\beta$.

intra-tubular hyaline casts on a semi-quantitative score. Five fields in each section were examined and a score ranging from 0-5 was considered, while grade 0 , showed an intact kidney and number 5, complete destruction. Biochemical evaluation including the superoxide dismutase (SOD) and transforming growth factor beta 1 (TGF- $\beta 1$ ) measurements were done by using standard kits purchased from ZellBio GmbH company (Germany) (Figures 2 and 3).

Kidney indices were measured by dividing the kidney weight $(\mathrm{g})$ to the rat body weight $(\mathrm{kg})$ in all groups (Table 2).

\section{Ethical issues}

This project was approved by the Ethics Committee of Bushehr University of Medical Sciences. Prior to the experiment, the protocols were confirmed to be in accordance with the guidelines of Animal Ethics Committee of Bushehr University of Medical Sciences (IR.BPUMS.REC.1395.196).

\section{Statistical analysis}

Results are shown as means \pm standard deviation (SD). Our data was analyzed using SPSS version 16. Our data were analyzed using Kruskal-Wallis and Mann-Whitney $\mathrm{U}$ tests to compare the severity of damages between our groups. $P<0.05$ was considered indicative of a statistical difference between them.

Results

\section{Vanadium effects on body weight}

Daily changes in the weights of animals during our experiment (28 days) are shown in Figure 1.

There were no significant differences in weight gain between resveratrol-treated compared with the control group. On the contrary, the body weight in the AMV group was significantly less than the control. Resveratrol in two doses (10 and $50 \mathrm{mg} / \mathrm{kg}$ ) had a dramatic effect for improving the body weight in the treated group.

Effects of resveratrol on biochemical parameters and relative kidney weight

The concentrations of sodium, potassium, urea, creatinine, and relative kidney weight are presented in Table 2.

Kidney indices did not change in each group, ruling out fibrosis as a destructive process. In the resveratrol treatment group (50 mg/kg), no alterations were observed compared with the control. Additionally, the serum levels of sodium and potassium had no statistical differences in our groups. Serum creatinine and urea were remarkably higher in AMV and AMV plus resveratrol $(10 \mathrm{mg} / \mathrm{kg}$ ) groups compared to the control, showing destructive nephrotic malformations. These parameters had no statistically significant differences compared with the control in AMV plus resveratrol group $(50 \mathrm{mg} / \mathrm{kg}$ ).

\section{Measurement of renal SOD and TGF- $\beta 1$}

The levels of SOD and TGF- $\beta 1$ parameters in each group were depicted in Figures 2 and 3.

Values were presented as units and picogram per mg protein of the left kidney, respectively. AMV injection (5 $\mathrm{mg} / \mathrm{kg})$ decreased the SOD level $(P<0.05)$ as compared with the control while it had no effects on the TGF- $\beta 1$ level. Treatment with resveratrol solution $(50 \mathrm{mg} / \mathrm{kg})$ markedly increased SOD levels in the vanadium exposed animals while it had no effects on the TGF $\beta-1$ level. Additionally, lower levels of this remedy $(10 \mathrm{mg} / \mathrm{kg})$ had no effects on both enzymes compared to the control.

\section{Pathological findings}

In the control samples, there were no specific pathological deteriorations or changes in glomeruli, tubules, interstitial tissues and/or peritubular capillaries in H\&E staining. On the contrary, microscopic views of the vanadium treated rats in high power field $(\times 100)$ revealed acute tubular 
Table 2. Results of kidney changes including blood urea nitrogen, creatinine, sodium, potassium and renal indices

\begin{tabular}{|c|c|c|c|c|c|}
\hline Variables & Control & Res50 & AMV5 & AMV5+Res10 & AMV5+Res50 \\
\hline $\mathrm{Na}(\mathrm{mEq} / \mathrm{dL})$ & $143.25 \pm 3.45$ & $139.25 \pm 2.43$ & $138.7 \pm 6.4$ & $148.7 \pm 8.4$ & $146.7 \pm 6.4$ \\
\hline $\mathrm{K}(\mathrm{mEq} / \mathrm{dL})$ & $3.895 \pm 0.24$ & $4.12 \pm 0.24$ & $3.39 \pm 0.74$ & $4.39 \pm 0.45$ & $4.49 \pm 0.78$ \\
\hline BUN (mg/dL) & $8.85 \pm 1.45$ & $9.21 \pm 1.45$ & $16.2 \pm 3.62^{*}$ & $14.48 \pm 5.34^{*}$ & $9.6 \pm 3.62$ \\
\hline $\mathrm{Cr}(\mathrm{mg} / \mathrm{dL})$ & $0.64 \pm 0.09$ & $0.72 \pm 0.09$ & $1.46 \pm 0.15^{*}$ & $1.26 \pm 0.45^{*}$ & $0.82 \pm 0.15$ \\
\hline Kidney indices (g/kg) & $3.25 \pm 0.74$ & $3.17 \pm 0.64$ & $3.34 \pm 0.48$ & $3.41 \pm 0.62$ & $3.16 \pm 0.37$ \\
\hline
\end{tabular}

Abbreviations: Van, vanadium; Res, resveratrol; BUN, blood urea nitrogen; $\mathrm{Cr}$, creatinine; AMV, ammonium metavanadate.

Data are presented as means \pm SD $(n=6)$. * means significant differences versus control at $P<0.05$.

injuries including tubular dilatation and attenuation with cytoplasmic apical blebbing, sloughing and finally anisometric vacuolization. In addition, peritubular congestion of the capillaries was observed (Figure 4).

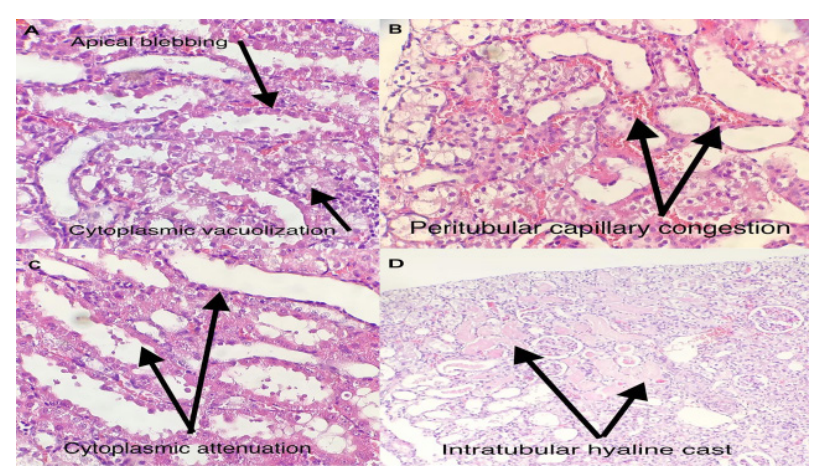

Figure 4. Photomictograph representative of acute tubular necrosis following intraperitoneal AMV injection ( $5 \mathrm{mg} / \mathrm{kg}$ for 14 days) in rats. Glomerular apparatus seems intact while cytoplasmic vacuolization, peritubular congestion, peritubular attenuation and finally intratubular hyaline casts are present in our images.

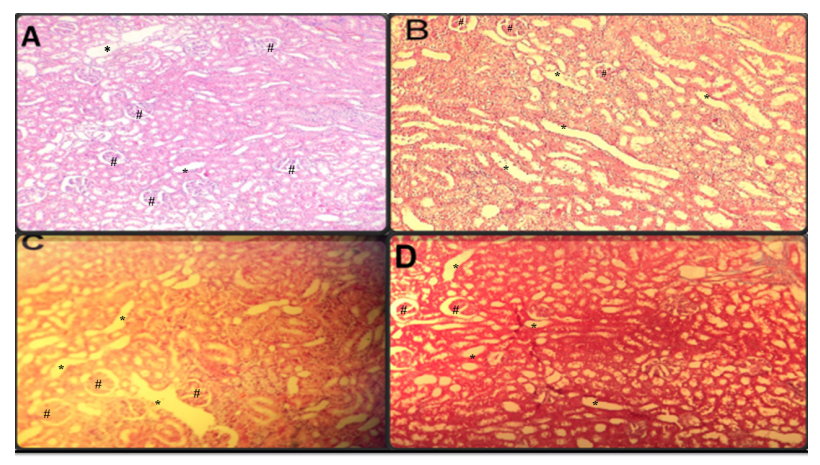

Figure 5. Micrograph of renal sections of rats from different groups (10x; H\&E stained). Control rats showing normal glomerular and tubular apparatus (A) while AMV treated rats demonstrating dilated tubules with normal glomerular arrangements (B). Resveratrol treated rats in lower dose $(10 \mathrm{mg} / \mathrm{kg})$ showing the reduced tubular dilatation(C) while in higher dose $(50 \mathrm{mg} / \mathrm{kg})$ had moderate changes compared to AMV treated rats. \# and * show glomeruli and tubules respectively.
The pathological views for our experimental groups are shown in Figure 5.

It is evident that vanadium treatment evoked marked pathological differences compared with normal saline. In addition, resveratrol treatment in both doses (10 and 50 $\mathrm{mg} / \mathrm{kg}$ ) could not ameliorate the destructive pathological properties induced with this agent qualitatively (Figure 5). Moreover, pathological views of resveratrol in two doses were compared with normal saline and vanadium treated groups (Figure 5). It shows no marked beneficial effects of resveratrol even in high dose treatment $(50 \mathrm{mg} / \mathrm{kg})$.

Finally, there were no signs of renal fibrosis in vanadatetreated samples since proliferative processes in addition to inflammatory and sclerotic malformations were not present in trichrome staining (data not shown).

\section{Discussion}

Vanadium belongs to the trace elements and its deficiency makes the human body at risk of experimental stresses and other different dangers. Several studies have pointed out that the liver and kidney are the main organs of accumulation of this element (10). In addition, the renal tissue as the specific site for the accumulation and excretion of the heavy metals like vanadium is prone to nephrotoxic properties (11). Resveratrol-treated groups among the AMV injected rats counteracted weight changes (Figure 1) (12). Overall, our data were in agreement with the previous articles reported the significant body weight decline following different doses of the vanadyl sulfate in rats (13). Another promising finding was the rise in the creatinine and blood urea of the treated rats compared with the control $(1.46 \pm 0.15$ and $16.2 \pm 3.62$ versus $0.64 \pm 0.09$ and $8.85 \pm 1.45)$. Interestingly, there were no clear changes in the serum sodium, potassium and kidney indices (Table 2), which were in agreement with the previous experiment in elderly rats demonstrating renal toxicities induced by this agent (1). It is noted that administration of the AMV significantly decreased the SOD activity in the renal tissues compared to the control $(16.4 \pm 2.31$ versus $51.2 \pm 5.34 \mathrm{unit} / \mathrm{mg}$ protein). SOD and catalase are the first enzymes known to counteract the oxidative stress injuries with preventive effects on the reactive hydroxyl radical in 
renal tissues (14). Interestingly, resveratrol treatment (50 $\mathrm{mg} / \mathrm{kg}$ ) moderately elevated SOD in vanadium treated group, thus preventing renal dysfunction induced by ROS. Our results approved the mechanism by which resveratrol increases SOD activity against ROS (15). Importantly, the level of renal TGF $\beta 1$ as a marker of fibrosis had no statistical difference with the normal control $(13.8 \pm 1.23$ versus $11.7 \pm 0.92 \mathrm{pg} / \mathrm{mg}$ protein). In inflammation, TGF $\beta 1$ is secreted by many cell types like macrophages. It has been reported that this cytokine at least has a dual role in wound healing and fibrogenesis (16). Further, it causes destructive effects on the renal tissues including synthesis of two types of collagen ( I and III) and other extracellular matrix proteins (17). It is well-known that glomerular injuries leading to sclerosis in addition to tubulointerstitial fibrosis are related to this particular agent (18). Based on our study, we have verified that AMV injection had no significant fibrotic effects in the renal tissues since there was no elevation in the amount of TGF- $\beta 1$ and pathological results. Moreover, the pathological views revealed tubular dilation and sloughing of epithelial cells. In addition, tubular cell necrosis and cytoplasmic blebbing were present. However, no marked abnormalities were observed in the glomeruli. Contrary to the previous report (7), there was no sign of renal fibrosis induced by the AMV injection in trichrome staining. A similar conclusion was reached by the previous reports (1, 19) which was in accordance with our results.

\section{Conclusions}

Our results enlighten the tubular injuries induced by the AMV injection in rats. Furthermore, histological findings provide strong evidence of kidney damage with no fibrosis. However, oral resveratrol with high dosage $(50 \mathrm{mg} / \mathrm{kg}$ ) has a minor role to repair the kidney function by prevention of the oxidative renal injury making its effectiveness questionable. Further studies are needed to confirm these findings and to determine how resveratrol might act on the AMV induced kidney injuries.

\section{Acknowledgments}

The authors would like to thank the authorities of Bushehr University of Medical Sciences for providing facilities. This manuscript was accepted as a poster presentation at the 4th International Congress of Nephrology and Urology, Tehran.

\section{Authors' contributions}

All authors participated in this experiment. RS and SZ designed and wrote the manuscript. HF, AJ, MN and $\mathrm{HH}$ performed the experiment. AE analyzed the pathological results. AM edited the manuscript.

\section{Conflicts of interest}

The authors declare that there is no conflict of interest.
Ethical considerations

Ethical issues (plagiarism, data fabrication and double publication) were completely observed by the author.

\section{Funding/Support}

This experiment was supported by the research deputy of Bushehr University of Medical Sciences as a research project (IR.BPUMS.REC.1395.166).

\section{References}

1. De la torre A, Granero S, Mayayo E, Corbella J, Domingo JL. Effect of age on vanadium nephrotoxicity in rats. Toxicol Lett. 1999;105:75-82

2. Wei CI, Al Bayati MA, Culbertson MR, Rosenblatt LS, Hansen LD..Acute toxicity of ammonium metavanadate in mice. J Toxicol Environ. 1982;10:673-87

3. Lobet JM, Domingo JL. Acute toxicity of vanadium compounds in rats and mice. Toxicol Lett. 1984;23:22731.

4. Athar M, Back JH, Kopelovich L, Bickers DR, Kim AL. Multiple molecular targets of resveratrol: Anticarcinogenic mechanisms. Arch Biochem Biophys. 2009;486:95-102.

5. Liang J, Tian S, Han J, Xiong P. Resveratrol as a therapeutic agent for renal fibrosis induced by unilateral ureteral obstruction. Ren Fail. 2014;36:285-91. doi: 10.3109/0886022X.2013.844644.

6. Al-Bayati MA, Xie Y, Mohr FC, Margolin SB, Giri SN. Effect of pirfenidone against vanadate-induced kidney fibrosis in rats. Biochem Pharmacol. 2002;64:517-25.

7. Soussi A, Abdennabi R, Ghorbel F, Murat JC, El Feki AF. Ameliorated Effects of (-)-Epigallocatechin Gallate Against Toxicity Induced by Vanadium in the Kidneys of Wistar Rats. Biol Trace Elem Res. 2017;180:239-245. doi: 10.1007/s12011-017-1004-4.

8. Saito M, Satoh S, Kojima N, Tada H, Sato M, Suzuki $\mathrm{T}$, et al. Effects of a phenolic compound, resveratrol, on the renal function and costimulatory adhesion molecule CD86 expression in rat kidneys with ischemia/ reperfusion injury. Arch Histol Cytol. 2005;68:41-9.

9. Soussi A, Croute F, Soleilhavoup JP, Kammoun A, ElFeki A. Impact of green tea on oxidative stress induced by ammonium metavanadate exposure in male rats. C R Biol. 2006;329:775-84. doi: 10.1016/j.crvi.2006.07.004.

10. Marouane W, Soussi A, Murat JC, Bezzine S, El Feki A. The protective effect of Malva sylvestris on rat kidney damaged by vanadium. Lipids Health Dis. 2011;10:65. doi: 10.1186/1476-511X-10-65.

11. Soussi A, Murat JC, Gaubin Y, Croute F, Soleilhavoup JP, El Feki A. Green tea drinking reduces the effects of vanadium poisoning in rat kidney. Food Sci Technol Res. 2009;15413-422 doi:10.3136/fstr.15.413.

12. Sanchez D, Ortega A, Domingo JL, Corbella J. Developmental toxicity evaluation of orthovanadate in the mouse. Biol Trace Elem Res. 1991;30:219-26.

13. Mohan M, Kamble S, Gadhi P, Kasture S. Protective effect of Solanum torvum on doxorubicin-induced nephrotoxicity in rats. Food Chem Toxicol. 2010;48:43640. doi: $10.1016 /$ j.fct.2009.10.042. 
14. Kavas GO, Ayral PA, Elhan AH. The effects of resveratrol on oxidant/antioxidant systems and their cofactors in rats. Adv Clin Exp Med. 2013;22:151-5.

15. Sharma A, Thakur R, Lingaraju MC, Kumar D, Mathesh K, Telang AG, et al. Betulinic acid attenuates renal fibrosis in rat chronic kidney disease model. Biomed Pharmacother. 2017;89:796-804. doi: 10.1016/j. biopha.2017.01.181.
16. Gressner AM, Weiskirchen R, Breitkopf K, Dooley S. Roles of TGF-beta in hepatic fibrosis. Front Biosci. 2002;7:d793-807.

17. Zhao YY, Cheng XL, Wei F, Bai X, Tan XJ, Lin RC, et al. Intrarenal metabolomic investigation of chronic kidney disease and its TGF- $\beta 1$ mechanism in induced-adenine rats using UPLC Q-TOF/HSMS/MSE. J Proteome Res. 2013;12:692-703. doi: 10.1021/pr3007792.

Copyright (c) 2019 The Author(s); Published by Nickan Research Institute. This is an open-access article distributed under the terms of the Creative Commons Attribution License (http://creativecommons.org/licenses/by/4.0), which permits unrestricted use, distribution, and reproduction in any medium, provided the original work is properly cited. 